\title{
Generalized coincidence theory for set-valued maps
}

\section{Donal O'Regan}

School of Mathematics, Statistics and Applied Mathematics, National University of Ireland, Galway, Ireland.

\author{
Communicated by R. Saadati
}

\begin{abstract}
This paper presents a coincidence theory for general classes of maps based on the notion of a $\Phi$-essential map (we will also discuss $\Phi$-epi maps). (C2017 All rights reserved.
\end{abstract}

Keywords: Essential maps, epi maps, coincidence points, homotopy.

2010 MSC: 47H04, 47H10, 54H25, 54M20.

\section{Introduction}

The notion of essential maps was introduced by Granas [7] and extended in the literature by many authors (see $[6,10,13,14])$. In Section 2 , using the notions of homotopy and $\Phi$-essential maps, we discuss the existence of coincidence points (i.e., $G(x) \cap \Phi(x) \neq \emptyset$ ) of maps $G$ and $\Phi$. The maps $G$ and $\Phi$ will belong to general classes of maps and will be defined on subsets of completely regular topological spaces. In particular we present continuation theorems and generalized topological transversality theorems. We will also discuss $\Phi$-epi maps $[5,13]$ in this paper.

\section{Essential maps}

Let $E$ be a completely regular topological space and $U$ an open subset of $E$. We consider classes $A$ and B of maps.

Definition 2.1. We say $F \in A(\bar{U}, E)$ (respectively $F \in B(\bar{U}, E)$ ) if $F: \bar{U} \rightarrow 2^{E}$ and $F \in A(\bar{U}, E)$ (respectively $F \in \mathbf{B}(\bar{U}, E))$; here $2^{E}$ denotes the family of nonempty subsets of $E$.

In this section we fix a $\Phi \in \mathrm{B}(\overline{\mathrm{U}}, \mathrm{E})$.

Definition 2.2. We say $F \in A_{\partial u}(\bar{U}, E)$ if $F \in A(\bar{U}, E)$ with $F(x) \cap \Phi(x)=\emptyset$ for $x \in \partial U$; here $\partial U$ denotes the boundary of $U$ in $E$.

Definition 2.3. Let $F \in A_{\partial u}(\bar{U}, E)$. We say $F: \bar{U} \rightarrow 2^{E}$ is $\Phi$-essential in $A_{\partial u}(\bar{U}, E)$ if for every map $\mathrm{J} \in \mathrm{A}_{\partial \mathrm{u}}(\overline{\mathrm{U}}, \mathrm{E})$ with $\left.\mathrm{J}\right|_{\partial \mathrm{u}}=\left.\mathrm{F}\right|_{\partial \mathrm{u}}$ there exists $\mathrm{x} \in \mathrm{U}$ with $\mathrm{J}(\mathrm{x}) \cap \Phi(\mathrm{x}) \neq \emptyset$.

Email address: donal . oregan@nuigalway.ie (Donal O'Regan)

doi:10.22436/jnsa.010.03.01

Received 2015-07-10 
Theorem 2.4. Let $\mathrm{E}$ be a completely regular (respectively normal) topological space, $\mathrm{U}$ an open subset of $\mathrm{E}$ and let $\mathrm{F} \in \mathrm{A}_{\partial \mathrm{u}}(\overline{\mathrm{U}}, \mathrm{E})$ be $\Phi$-essential in $\mathrm{A}_{\partial \mathrm{u}}(\overline{\mathrm{U}}, \mathrm{E})$. Suppose there exists a map $\mathrm{H}: \overline{\mathrm{U}} \times[0,1] \rightarrow 2^{\mathrm{E}}$ with $\mathrm{H}(., \eta().) \in$ $\mathrm{A}(\overline{\mathrm{U}}, \mathrm{E})$ for any continuous function $\eta: \overline{\mathrm{U}} \rightarrow[0,1]$ with $\eta(\partial \mathrm{U})=0, \Phi(\mathrm{x}) \cap \mathrm{H}_{\mathrm{t}}(\mathrm{x})=\emptyset$ for any $\mathrm{x} \in \partial \mathrm{U}$ and $\mathrm{t} \in(0,1], \mathrm{H}_{0}=\mathrm{F}$ and $\{\mathrm{x} \in \overline{\mathrm{U}}: \Phi(\mathrm{x}) \cap \mathrm{H}(\mathrm{x}, \mathrm{t}) \neq \emptyset$ for some $\mathrm{t} \in[0,1]\}$ is compact (respectively closed). Then there exists $\mathrm{x} \in \mathrm{U}$ with $\Phi(\mathrm{x}) \cap \mathrm{H}_{1}(\mathrm{x}) \neq \emptyset$; here $\mathrm{H}_{\mathrm{t}}(\mathrm{x})=\mathrm{H}(\mathrm{x}, \mathrm{t})$.

Proof. Let

$$
\mathrm{D}=\{x \in \overline{\mathrm{U}}: \Phi(x) \cap \mathrm{H}(x, \mathrm{t}) \neq \emptyset \text { for some } \mathrm{t} \in[0,1]\} .
$$

Note $\mathrm{D} \neq \emptyset$ since $\mathrm{F}$ is $\Phi$-essential in $A_{\partial \mathrm{u}}(\overline{\mathrm{U}}, \mathrm{E})$. Also $\mathrm{D}$ is compact (respectively closed) if $\mathrm{E}$ is a completely regular (respectively normal) topological space. Note $\mathrm{D} \cap \partial \mathrm{U}=\emptyset$ (note $\mathrm{H}_{0}=\mathrm{F}$ so for $\mathrm{t}=0$ we have $\Phi(x) \cap \mathrm{H}_{0}(x)=\emptyset$ for $x \in \partial \mathrm{U}$ since $\left.\mathrm{F} \in \mathrm{A}_{\partial \mathrm{u}}(\overline{\mathrm{U}}, \mathrm{E})\right)$. Thus there exists a continuous map $\mu: \overline{\mathrm{U}} \rightarrow[0,1]$ with $\mu(\partial \mathrm{U})=0$ and $\mu(\mathrm{D})=1$. Define $\mathrm{J}: \overline{\mathrm{U}} \rightarrow 2^{\mathrm{E}}$ by $\mathrm{J}(\mathrm{x})=\mathrm{H}(\mathrm{x}, \mu(\mathrm{x}))$. Note $\mathrm{J} \in A_{\partial \mathrm{u}}(\overline{\mathrm{U}}, \mathrm{E})$ with $\left.\mathrm{J}\right|_{\partial \mathrm{u}}=\left.\mathrm{F}\right|_{\partial \mathrm{u}}$ (note if $x \in \partial U$, then $J(x)=H_{0}(x)=F(x)$ and $\left.J(x) \cap \Phi(x)=F(x) \cap \Phi(x)=\emptyset\right)$ ). Now since $F$ is $\Phi$-essential in $A_{\partial u}(\bar{U}, E)$ then there exists an $x \in U$ with $J(x) \cap \Phi(x) \neq \emptyset$ (i.e., $H_{\mu(x)}(x) \cap \Phi(x) \neq \emptyset$ ), and thus $x \in D$ so $\mu(x)=1$ and as a result, $H_{1}(x) \cap \Phi(x) \neq \emptyset$.

We now give one example of how Theorem 2.4 can be applied. First we recall some concepts from the literature. Let $E$ be a Banach space, $E^{\star}$ the conjugate space of $E$, and $(.,$.$) the duality between E^{\star}$ and $E$. Let $X$ be a subset of $E$. Now

(i). $F: X \rightarrow E^{\star}$ is monotone if $(F(x)-F(y), x-y) \geqslant 0$ for all $x, y \in X$;

(ii). $F: X \rightarrow E^{\star}$ is of class $(S)_{+}$if for any sequence $\left(x_{j}\right)$ in $X$, for which $x_{j} \rightarrow x$ and $\lim \sup \left(F\left(x_{j}\right), x_{j}-x\right) \leqslant$ 0 , we have $x_{j} \rightarrow x$;

(iii). $F: X \rightarrow E^{\star}$ is maximal monotone if it is monotone and $\left(x^{\star}-F(y), x-y\right) \geqslant 0$ for all $y \in X$ implies $x \in X$ and $F(x)=x^{\star}$;

(iv). $F: X \rightarrow E^{\star}$ is hemicontinuous if $F(x+t y) \rightarrow F(x)$ as $t \rightarrow 0$;

(v). $F: X \rightarrow E^{\star}$ is demicontinuous if $y \rightarrow x$ implies $F(y) \rightarrow F(x)$.

For our next result, $E$ will be a reflexive Banach space. We assume that $E$ is endowed with an equivalent norm, with respect to which, $E$ and $E^{\star}$ are locally uniformly convex (this is always possible [3, 4]). Then there exists a unique mapping (duality mapping) $J: E \rightarrow E^{\star}$ such that $(J(x), x)=|x|^{2}=|J x|^{2}$ for all $x \in \mathrm{E}$. Moreover $\mathrm{J}$ is bijective, bicontinuous, monotone, and of class $(\mathrm{S})_{+}$(see [4, pp 20]). To apply Theorem 2.4 below let $E, E^{\star}$ and $J$ be as above, $U$ a nonempty open subset of $E$ and $T: E \rightarrow E^{\star}$ a fixed monotone, hemicontinuous mapping. We know $\mathrm{T}$ is demicontinuous $[8,9]$. Recall also that any monotone hemicontinuous mapping is maximal monotone. As a result, since $T: E \rightarrow E^{\star}$ is maximal monotone, then $\mathrm{J}+\mathrm{T}$ is bijective and $(\mathrm{J}+\mathrm{T})^{-1}: \mathrm{E}^{\star} \rightarrow \mathrm{E}$ is demicontinuous. We will apply Theorem 2.4 below with $\Phi(x)=i(x)$ (the identity map) for $x \in \bar{U}$ (and $B(\bar{U}, E)=C(\bar{U}, E)$ is the class of continuous mappings from $\overline{\mathrm{U}}$ to $\mathrm{E})$.

Definition 2.5. We let $E M(\bar{U}, E)$ denote the maps $f=(J+T)^{-1}(J-F): \bar{U} \rightarrow E$ where $F: \bar{U} \rightarrow E^{\star}$ is demicontinuous, and of class $(S)_{+}$. In this case we say $f=(J+T)^{-1}(J-F) \in E M(\bar{U}, E)$.

Definition 2.6. We say $f=(J+T)^{-1}(J-F) \in E M_{\partial u}(\bar{U}, E)$ if $f \in E M(\bar{U}, E)$ and $(T+F)(x) \neq 0$ (i.e., $\left.x \neq(J+T)^{-1}(J-F)(x)\right)$ for $x \in \partial U$.

Remark 2.7. Note if $x \in \overline{\mathrm{U}}$ with $x=f(x)=(J+T)^{-1}(J-F)(x)$ then it is clear that $(T+F)(x)=0$. Conversely if $x \in \bar{U}$ and $(T+F)(x)=0$ then $(J-F)(x)=(J+T)(x)$ so $x=f(x)=(J+T)^{-1}(J-F)(x)$.

Definition 2.8. A map $f=(J+T)^{-1}(J-F) \in E M_{\partial u}(\bar{U}, E)$ is essential in $E M_{\partial u}(\bar{U}, E)$ if for every $g=$ $(J+T)^{-1}(J-G) \in E M_{\partial u}(\bar{U}, E)$ with $\left.g\right|_{\partial u}=\left.f\right|_{\partial u}\left(i . e .,\left.G\right|_{\partial u}=\left.F\right|_{\partial u}\right.$ since $(J+T)^{-1}$ is injective), there exists $x \in \overline{\mathrm{U}}$ with $(T+F)(x)=0$ (i.e., $\left.x=(J+T)^{-1}(J-F)(x)\right)$. 
Corollary 2.9. Let $\mathrm{E}, \mathrm{E}^{\star}, \mathrm{U}, \mathrm{J}$ and $\mathrm{T}$ be as above and let $\mathrm{f}=(\mathrm{J}+\mathrm{T})^{-1}(\mathrm{~J}-\mathrm{F}) \in \mathrm{EM} \mathrm{\partial u}(\overline{\mathrm{U}}, \mathrm{E})$ be essential in $\mathrm{EM}_{\partial \mathrm{u}}(\overline{\mathrm{U}}, \mathrm{E})$. Suppose there exists a map $\Psi: \overline{\mathrm{U}} \times[0,1] \rightarrow \mathrm{E}^{\star}$ with $\left(\mathrm{T}+\Psi_{\mathrm{t}}\right)(\mathrm{x}) \neq 0\left(\right.$ i.e., $\left.\mathrm{x} \neq(\mathrm{J}+\mathrm{T})^{-1}\left(\mathrm{~J}-\Psi_{\mathrm{t}}\right)(\mathrm{x})\right)$ for $\mathrm{x} \in \partial \mathrm{U}$ and $\mathrm{t} \in(0,1]$ (here $\left.\Psi_{\mathrm{t}}(\mathrm{x})=\Psi(\mathrm{x}, \mathrm{t})\right), \Psi_{0}=\mathrm{F}$, and

$$
\begin{gathered}
\left\{\begin{array}{l}
\text { for any continuous function } \eta: \overline{\mathrm{U}} \rightarrow[0,1] \text { with } \eta(\partial \mathrm{U})=0, \\
\text { the map } \Psi(., \eta(.)) \text { is demicontinuous and of class }(\mathrm{S})_{+},
\end{array}\right. \\
\left\{\begin{array}{l}
\text { for any sequence }\left\{x_{j}\right\} \text { in } \overline{\mathrm{U}} \text { with } \mathrm{x}_{j} \rightarrow x \text { and } \\
\text { any sequence }\left\{\mathrm{t}_{j}\right\} \text { in }[0,1] \text { with } \mathrm{t}_{j} \rightarrow \mathrm{t} \text { for which } \\
\lim \sup \left(\Psi\left(\mathrm{x}_{j}, \mathrm{t}_{j}\right), x_{j}-x\right) \leqslant 0, \text { we have } \Psi\left(x_{j}, \mathrm{t}_{j}\right) \rightarrow \Psi(x, t) .
\end{array}\right.
\end{gathered}
$$

Then, there exists $x \in \mathrm{U}$ with $0=\left(\mathrm{T}+\Psi_{1}\right)(\mathrm{x})$ (i.e., $\mathrm{x}=(\mathrm{J}+\mathrm{T})^{-1}\left(\mathrm{~J}-\Psi_{1}\right)(\mathrm{x})$ ).

Proof. We apply Theorem 2.4 with $\Phi=i$ and $H(x, t)=(J+T)^{-1}\left(J-\Psi_{t}\right)(x)$. The result follows immediately from Theorem 2.4 once we show

$$
\mathrm{D}=\left\{x \in \overline{\mathrm{U}}: x=(J+T)^{-1}\left(J-\Psi_{\mathrm{t}}\right)(x) \text { for some } \mathrm{t} \in[0,1]\right\}
$$

is closed (note from (2.1) that $\mathrm{H}(., \eta().) \in E M(\overline{\mathrm{U}}, \mathrm{E})$ for any continuous function $\eta: \overline{\mathrm{U}} \rightarrow[0,1]$ with $\eta(\partial U)=0)$. To show $D$ is closed let $\left(x_{j}\right)$ be a sequence in $D$ with $x_{j} \rightarrow x$. Then $\left(T+\Psi_{t_{j}}\right)\left(x_{j}\right)=0$ for some sequence $\left\{t_{j}\right\}$ in $[0,1]$ (without loss of generality assume $t_{j} \rightarrow t$ ). Also note that since $T$ is monotone then

$$
\left(\Psi\left(x_{j}, t_{j}\right), x_{j}-x\right)=\left(-T x_{j}+T x, x_{j}-x\right)+\left(-T x, x_{j}-x\right) \leqslant\left(-T x, x_{j}-x\right),
$$

so since $x_{j} \rightarrow x$ we have lim sup $\left(\Psi\left(x_{j}, t_{j}\right), x_{j}-x\right) \leqslant 0$. Now (2.2) implies $\Psi\left(x_{j}, t_{j}\right) \rightarrow \Psi(x, t)$. This together with $\left(T+\Psi_{t_{j}}\right)\left(x_{j}\right)=0$ and $T$ demicontinuous gives $\left(T+\Psi_{t}\right)(x)=0$, so $x \in D$. Thus $D$ is closed.

Remark 2.10. In Corollary 2.9 we could replace $T: E \rightarrow E^{\star}$ a monotone, hemicontinuous mapping with $\mathrm{T}: \mathrm{E} \rightarrow \mathrm{E}^{\star}$ a maximal monotone mapping. To see this we need to show $\mathrm{D}$ (in Corollary 2.9) is closed. Let $\left(x_{j}\right)$ be a sequence in D with $x_{j} \rightarrow x$. Then $\left(T+\Psi_{t_{j}}\right)\left(x_{j}\right)=0$ for some sequences $\left\{t_{j}\right\}$ in $[0,1]$ (without loss of generality assume $\left.t_{j} \rightarrow t\right)$. As in Corollary 2.9 we obtain $\Psi\left(x_{j}, t_{j}\right) \rightarrow \Psi(x, t)$. Now pass to the limit in (here $y \in \overline{\mathrm{u}}$ ),

$$
\left(-\Psi\left(x_{j}, t_{j}\right)-T y, x_{j}-y\right)=\left(T x_{j}-T y, x_{j}-y\right) \geqslant 0,
$$

and we obtain

$$
(-\Psi(x, t)-T y, x-y) \geqslant 0 .
$$

Now since $T$ is a maximal monotone mapping we have $T x=-\Psi(x, t)$, so $x \in D$ and $D$ is closed.

Remark 2.11. Looking through the proof of Corollary 2.9 (see also $[1,4,14]$ it is easy to see that (2.1) and (2.2) could be replaced by the condition:

$$
\left\{\begin{array}{l}
\text { for any sequence }\left\{x_{j}\right\} \text { in } \bar{U} \text { with } x_{j} \rightarrow x \text { and } \\
\text { any sequence }\left\{t_{j}\right\} \text { in }[0,1] \text { with } t_{j} \rightarrow t \text { for which } \\
\limsup \left(\Psi\left(x_{j}, t_{j}\right), x_{j}-x\right) \leqslant 0, \text { we have } \\
x_{j} \rightarrow x \text { and } \Psi\left(x_{j}, t_{j}\right) \rightarrow \Psi(x, t) .
\end{array}\right.
$$

Next we present a topological transversality theorem for $\Phi$-essential maps. To achieve this we need to change Definition 2.3 (see Definition 2.13 below).

Definition 2.12. Let $E$ be a completely regular (respectively normal) topological space, and $U$ an open subset of $E$. Let $F, G \in A_{\partial u}(\bar{U}, E)$. We say $F \cong G$ in $A_{\partial u}(\bar{U}, E)$ if there exists a map $H: \bar{U} \times[0,1] \rightarrow 2^{E}$ with $H(., \eta().) \in A(\bar{U}, E)$ for any continuous function $\eta: \bar{U} \rightarrow[0,1]$ with $\eta(\partial U)=0, H_{t}(x) \cap \Phi(x)=\emptyset$ for any $x \in \partial U$ and $t \in[0,1], H_{1}=F, H_{0}=G$ and $\{x \in \bar{U}: \Phi(x) \cap H(x, t) \neq \emptyset$ for some $t \in[0,1]\}$ is compact (respectively closed); here $H_{t}(x)=H(x, t)$ ). 
The following condition will be assumed in our next two results:

$$
\cong \text { is an equivalence relation in } A_{\partial u}(\bar{U}, E) \text {. }
$$

Definition 2.13. Let $F \in A_{\partial u}(\bar{U}, E)$. We say $F: \bar{U} \rightarrow 2^{E}$ is $\Phi$-essential in $A_{\partial u}(\bar{U}, E)$ if for every map $J \in A_{\partial u}(\bar{U}, E)$ with $\left.J\right|_{\partial u}=\left.F\right|_{\partial u}$ and $J \cong F$ in $A_{\partial u}(\bar{U}, E)$ there exists $x \in U$ with $J(x) \cap \Phi(x) \neq \emptyset$. Otherwise $F$ is $\Phi$-inessential in $A_{\partial u}(\bar{U}, E)$, i.e., there exists a map $J \in A_{\partial u}(\bar{U}, E)$ with $\left.J\right|_{\partial u}=\left.F\right|_{\partial u}$ and $\mathrm{J} \cong \mathrm{F}$ in $A_{\partial \mathrm{u}}(\overline{\mathrm{U}}, \mathrm{E})$ with $\mathrm{J}(\mathrm{x}) \cap \Phi(\mathrm{x})=\emptyset$ for all $\mathrm{x} \in \overline{\mathrm{U}}$.

Theorem 2.14. Let $\mathrm{E}$ be a completely regular (respectively normal) topological space, $\mathrm{U}$ an open subset of $\mathrm{E}$, and assume (2.3) holds. Suppose $\mathrm{F} \in \mathrm{A}_{\mathrm{\partial u}}(\overline{\mathrm{U}}, \mathrm{E})$ and assume the following condition holds:

$$
\left\{\begin{array}{l}
\text { if there exists a map } \mathrm{G} \in \mathrm{A}_{\mathrm{\partial u}}(\overline{\mathrm{U}}, \mathrm{E}) \text { with } \mathrm{G} \cong \mathrm{F} \text { in } \mathrm{A}_{\partial \mathrm{u}}(\overline{\mathrm{U}}, \mathrm{E}) \\
\text { and } \mathrm{G}(\mathrm{x}) \cap \Phi(\mathrm{x})=\emptyset \text { for all } \mathrm{x} \in \overline{\mathrm{U}} \text { and if } \mathrm{H} \text { is the map defined } \\
\text { in Definition } 2.12 \text { and } \mu: \overline{\mathrm{U}} \rightarrow[0,1] \text { is any continuous map with } \\
\mu(\partial \mathrm{U})=0 \text {, then }\{x \in \overline{\mathrm{U}}: \emptyset \neq \Phi(\mathrm{x}) \cap \mathrm{H}(\mathrm{x}, \mathrm{t} \mu(\mathrm{x})) \text { for some } \mathrm{t} \in[0,1]\} \text { is closed. }
\end{array}\right.
$$

Then the following are equivalent:

(i). $\mathrm{F}$ is $\Phi$-inessential in $\mathrm{A}_{\partial \mathrm{u}}(\overline{\mathrm{U}}, \mathrm{E})$;

(ii). there exists a map $\mathrm{G} \in \mathrm{A}_{\partial \mathrm{u}}(\overline{\mathrm{U}}, \mathrm{E})$ with $\mathrm{G} \cong \mathrm{F}$ in $\mathrm{A}_{\partial \mathrm{u}}(\overline{\mathrm{U}}, \mathrm{E})$ and $\mathrm{G}(\mathrm{x}) \cap \Phi(\mathrm{x})=\emptyset$ for all $\mathrm{x} \in \overline{\mathrm{U}}$.

Proof. (i) implies (ii) immediately. Next we prove (ii) implies (i). Suppose there exists a map $G \in$ $A_{\partial u}(\bar{U}, E)$ with $G \cong F$ in $A_{\partial u}(\bar{U}, E)$ and $G(x) \cap \Phi(x)=\emptyset$ for all $x \in \bar{U}$. Let $H: \bar{U} \times[0,1] \rightarrow 2^{E}$ with $H(., \eta().) \in A(\bar{U}, E)$ for any continuous function $\eta: \bar{U} \rightarrow[0,1]$ with $\eta(\partial U)=0, H_{t}(x) \cap \Phi(x)=\emptyset$ for any $x \in \partial U$ and $t \in[0,1], H_{0}=F, H_{1}=G$ (here $\left.H_{t}(x)=H(x, t)\right)$ and $\{x \in \bar{U}: \Phi(x) \cap H(x, t) \neq$ $\emptyset$ for some $t \in[0,1]\}$ is compact (respectively closed). Consider

$$
\mathrm{D}=\{x \in \overline{\mathrm{U}}: \Phi(x) \cap \mathrm{H}(\mathrm{x}, \mathrm{t}) \neq \emptyset \text { for some } \mathrm{t} \in[0,1]\}
$$

If $\mathrm{D}=\emptyset$, then in particular $\emptyset=\Phi(x) \cap \mathrm{H}(x, 0)=\Phi(x) \cap \mathrm{F}(\mathrm{x})$ for $x \in \overline{\mathrm{U}}$ so $\mathrm{F}$ is $\Phi$-inessential in $A_{\partial u}(\overline{\mathrm{U}}, \mathrm{E})$ (take $J=F$ in Definition 2.13). Next suppose $D \neq \emptyset$. Note $D$ is compact (respectively closed) if $E$ is a completely regular (respectively normal) topological space. Also $\mathrm{D} \cap \partial \mathrm{U}=\emptyset$. Thus there exists a continuous map $\mu: \overline{\mathrm{U}} \rightarrow[0,1]$ with $\mu(\partial \mathrm{U})=0$ and $\mu(\mathrm{D})=1$. Define $J: \overline{\mathrm{U}} \rightarrow 2^{\mathrm{E}}$ by $J(x)=\mathrm{H}(\mathrm{x}, \mu(\mathrm{x}))$. Note $\mathrm{J} \in \mathrm{A}(\overline{\mathrm{U}}, \mathrm{E})$ and $\left.\mathrm{J}\right|_{\partial \mathrm{u}}=\left.\mathrm{H}_{0}\right|_{\partial \mathrm{u}}=\left.\mathrm{F}\right|_{\partial \mathrm{u}}$. Also note if there exists an $\mathrm{x} \in \overline{\mathrm{U}}$ with $\mathrm{J}(\mathrm{x}) \cap \Phi(\mathrm{x}) \neq \emptyset$ then $\mathrm{x} \in \mathrm{D}$ so $\mu(x)=1$, i.e., $G(x) \cap \Phi(x) \neq \emptyset$, a contradiction. Thus $\mathrm{J} \in A_{\partial u}(\bar{U}, E)$ and $\left.J\right|_{\partial u}=\left.F\right|_{\partial u}$ and $J(x) \cap \Phi(x)=\emptyset$ for $x \in \overline{\mathrm{U}}$. We now claim

$$
\mathrm{J} \cong \mathrm{F} \text { in } \mathrm{A}_{\partial \mathrm{u}}(\overline{\mathrm{U}}, \mathrm{E})
$$

If (2.5) is true, then $F$ is $\Phi$-inessential in $A_{\partial u}(\bar{U}, E)$.

It remains to show (2.5). Let $\mathrm{Q}: \overline{\mathrm{U}} \times[0,1] \rightarrow 2^{\mathrm{E}}$ be given by $\mathrm{Q}(\mathrm{x}, \mathrm{t})=\mathrm{H}(\mathrm{x}, \mathrm{t} \mu(x))$. Note $\mathrm{Q}(., \eta().) \in$ $A(\bar{U}, E)$ for any continuous function $\eta: \bar{U} \rightarrow[0,1]$ with $\eta(\partial U)=0$ and (see (2.4) and Definition 2.12)

$$
\{x \in \overline{\mathrm{U}}: \emptyset \neq \Phi(x) \cap \mathrm{Q}(\mathrm{x}, \mathrm{t})=\Phi(\mathrm{x}) \cap \mathrm{H}(\mathrm{x}, \mathrm{t} \mu(\mathrm{x})) \text { for some } \mathrm{t} \in[0,1]\}
$$

is compact (respectively closed). Note $\mathrm{Q}_{0}=\mathrm{F}$ and $\mathrm{Q}_{1}=\mathrm{J}$. Finally if there exists a $\mathrm{t} \in[0,1]$ and $x \in \partial \mathrm{U}$ with $\Phi(x) \cap Q_{t}(x) \neq \emptyset$, then $\Phi(x) \cap H_{t \mu(x)}(x) \neq \emptyset$ so $x \in D$ and so $\mu(x)=1$, i.e., $\Phi(x) \cap H_{t}(x) \neq \emptyset$, a contradiction. Thus (2.5) holds.

Theorem 2.15. Let $\mathrm{E}$ be a completely regular (respectively normal) topological space, $\mathrm{U}$ an open subset of $\mathrm{E}$ and assume (2.3) and (2.4) hold. Suppose $\mathrm{F}$ and $\mathrm{G}$ are two maps in $\mathrm{A}_{\partial \mathrm{u}}(\overline{\mathrm{U}}, \mathrm{E})$ with $\mathrm{F} \cong \mathrm{G}$ in $\mathrm{A}_{\partial \mathrm{u}}(\overline{\mathrm{U}}, \mathrm{E})$. Then $\mathrm{F}$ is $\Phi$-essential in $\mathrm{A}_{\partial \mathrm{u}}(\overline{\mathrm{U}}, \mathrm{E})$ if and only if $\mathrm{G}$ is $\Phi$-essential in $\mathrm{A}_{\partial \mathrm{u}}(\overline{\mathrm{U}}, \mathrm{E})$. 
Proof. $F$ is $\Phi$-inessential in $A_{\partial u}(\bar{U}, E)$ iff there exists a map $\Psi \in A_{\partial u}(\bar{U}, E)$ with $F \cong \Psi$ in $A_{\partial u}(\bar{U}, E)$ and $\Phi(x) \cap \Psi(x)=\emptyset$ for $x \in \bar{U}$ iff (since (2.3) holds) there exists a map $\Psi \in A_{\partial u}(\bar{U}, E)$ with $G \cong \Psi$ in $A_{\partial u}(\bar{U}, E)$ and $\Phi(x) \cap \Psi(x)=\emptyset$ for $x \in \bar{U}$ iff $G$ is $\Phi$-inessential in $A_{\partial u}(\bar{U}, E)$.

Remark 2.16. In Definition 2.13 if $\phi$ and $\eta$ are in $A_{\partial u}(\bar{U}, E)$ with $\left.\phi\right|_{\partial u}=\left.\eta\right|_{\partial u}$, is $\phi \cong \eta$ in $A_{\partial u}(\bar{U}, E)$ ? Certainly this is true for certain classes of maps (see $[2,11,12])$. This is also true for the maps considered in $\mathrm{EM}_{\partial \mathrm{u}}(\overline{\mathrm{U}}, \mathrm{E})$ (see Definition 2.6) with the definition of $\cong$ given below (see (2.6)). Let $f=(J+T)^{-1}(J-F)$, $g=(J+T)^{-1}(J-G)$ be in $E M_{\partial u}(\bar{U}, E)$ (here $F, G: \bar{U} \rightarrow E^{\star}$ are demicontinuous, and of class $\left.(S)_{+}\right)$. We say $f \cong g$ in $\operatorname{EM}_{\partial u}(\bar{U}, E)$ if the following condition holds:

$$
\left\{\begin{array}{l}
\text { there exists } \Psi: \bar{U} \times[0,1] \rightarrow E^{\star} \text { such that } \Psi_{0}=F, \\
\Psi_{1}=G,\left(T+\Psi_{t}\right)(x) \neq 0 \text { for } x \in \partial U, \text { and } t \in(0,1), \\
\text { and for any sequence }\left\{x_{j}\right\} \text { in } \bar{U} \text { with } x_{j} \rightarrow x \text { and } \\
\text { any sequence }\left\{t_{j}\right\} \text { in }[0,1] \text { with } t_{j} \rightarrow t \text { for which } \\
\text { limsup }\left(\Psi\left(x_{j}, t_{j}\right), x_{j}-x\right) \leqslant 0, \text { we have } x_{j} \rightarrow x \text { and } \Psi\left(x_{j}, t_{j}\right) \rightarrow \Psi(x, t) .
\end{array}\right.
$$

Now suppose $f$ and $g$ are as above with $\left.f\right|_{\partial u}=\left.g\right|_{\partial u}$ (i.e., $\left.F\right|_{\partial u}=\left.G\right|_{\partial u}$ since $(J+T)^{-1}$ is injective). Now take $\Psi(x, t)=(1-t) F(x)+t G(x)$. First note for $x \in \partial U$ and $t \in[0,1]$ that (note $\left.F\right|_{\partial u}=\left.G\right|_{\partial u}$ )

$$
\left(T+\Psi_{t}\right)(x)=(T+(1-t) F+t G)(x)=(T+F)(x) \neq 0,
$$

since $f \in E M_{\partial u}(\bar{U}, E)$. This together with [4, Proposition 12] guarantees that $f \cong g$ in $E M_{\partial u}(\bar{U}, E)$.

We now generalize the theory presented above. Let $E$ be a topological vector space (so automatically a completely regular space), $Y$ a topological vector space, and $U$ an open subset of $E$. Also let $L:$ dom $L \subseteq$ $E \rightarrow Y$ be a linear single-valued map; here dom $L$ is a vector subspace of $E$. Finally $T: E \rightarrow Y$ will be a linear single-valued map with $L+T$ : dom $L \rightarrow Y$ a bijection; for convenience we say $T \in H_{L}(E, Y)$.

Definition 2.17. We say $F \in A(\bar{U}, Y ; L, T)$ (respectively $F \in B(\bar{U}, Y ; L, T)$ ) if $F: \bar{U} \rightarrow 2^{Y}$ and $(L+T)^{-1}(F+T) \in$ $A(\bar{U}, E)$ (respectively $(L+T)^{-1}(F+T) \in B(\bar{U}, E)$ ).

We now fix a $\Phi \in B(\bar{U}, Y ; L, T)$.

Definition 2.18. We say $F \in A_{\partial u}(\bar{U}, Y ; L, T)$ if $F \in A(\bar{U}, Y ; L, T)$ with $(L+T)^{-1}(F+T)(x) \cap(L+T)^{-1}(\Phi+$ $\mathrm{T})(x)=\emptyset$ for $x \in \partial u$.

Definition 2.19. Let $F \in A_{\partial u}(\bar{U}, Y ; L, T)$. We say $F$ is $(L, T) \Phi$-essential in $A_{\partial u}(\bar{U}, Y ; L, T)$ if for every map $\mathrm{J} \in \mathrm{A}_{\partial \mathrm{u}}(\overline{\mathrm{U}}, \mathrm{Y} ; \mathrm{L}, \mathrm{T})$ with $\left.\mathrm{J}\right|_{\partial \mathrm{u}}=\left.\mathrm{F}\right|_{\partial \mathrm{u}}$ there exists $\mathrm{x} \in \mathrm{U}$ with $(\mathrm{L}+\mathrm{T})^{-1}(\mathrm{~J}+\mathrm{T})(\mathrm{x}) \cap(\mathrm{L}+\mathrm{T})^{-1}(\Phi+\mathrm{T})(\mathrm{x}) \neq \emptyset$.

Theorem 2.20. Let $\mathrm{E}$ be a topological vector space (so automatically completely regular), $\mathrm{Y}$ a topological vector space, $\mathrm{U}$ an open subset of $\mathrm{E}, \mathrm{L}: \operatorname{dom} \mathrm{L} \subseteq \mathrm{E} \rightarrow \mathrm{Y}$ a linear single-valued map, and $\mathrm{T} \in \mathrm{H}_{\mathrm{L}}(\mathrm{E}, \mathrm{Y})$. Let $\mathrm{F} \in$ $A_{\partial u}(\bar{U}, Y ; L, T)$ be $(L, T) \Phi$-essential in $A_{\partial u}(\bar{U}, Y ; L, T)$. Suppose there exists a map $\mathrm{H}: \overline{\mathrm{U}} \times[0,1] \rightarrow 2^{\mathrm{Y}}$ with $(\mathrm{L}+\mathrm{T})^{-1}(\mathrm{H}(., \eta())+.\mathrm{T}().) \in \mathrm{A}(\overline{\mathrm{U}}, \mathrm{E})$ for any continuous function $\eta: \overline{\mathrm{U}} \rightarrow[0,1]$ with $\eta(\partial \mathrm{U})=0,(\mathrm{~L}+$ $\mathrm{T})^{-1}\left(\mathrm{H}_{\mathrm{t}}+\mathrm{T}\right)(\mathrm{x}) \cap(\mathrm{L}+\mathrm{T})^{-1}(\Phi+\mathrm{T})(\mathrm{x})=\emptyset$ for any $\mathrm{x} \in \partial \mathrm{U}$ and $\mathrm{t} \in(0,1], \mathrm{H}_{0}=\mathrm{F}$ (here $\mathrm{H}_{\mathrm{t}}(\mathrm{x})=\mathrm{H}(\mathrm{x}, \mathrm{t})$ ) and $\left\{x \in \overline{\mathrm{U}}:(\mathrm{L}+\mathrm{T})^{-1}(\Phi+\mathrm{T})(\mathrm{x}) \cap(\mathrm{L}+\mathrm{T})^{-1}\left(\mathrm{H}_{\mathrm{t}}+\mathrm{T}\right)(\mathrm{x}) \neq \emptyset\right.$ for some $\left.\mathrm{t} \in[0,1]\right\}$ is compact. Then there exists $x \in \mathrm{U}$ with $(\mathrm{L}+\mathrm{T})^{-1}\left(\mathrm{H}_{1}+\mathrm{T}\right)(\mathrm{x}) \cap(\mathrm{L}+\mathrm{T})^{-1}(\Phi+\mathrm{T})(\mathrm{x}) \neq \emptyset$.

Proof. Let

$$
\mathrm{D}=\left\{x \in \overline{\mathrm{U}}:(\mathrm{L}+\mathrm{T})^{-1}(\Phi+\mathrm{T})(\mathrm{x}) \cap(\mathrm{L}+\mathrm{T})^{-1}\left(\mathrm{H}_{\mathrm{t}}+\mathrm{T}\right)(\mathrm{x}) \neq \emptyset \text { for some } \mathrm{t} \in[0,1]\right\} .
$$

Note $\mathrm{D} \neq \emptyset$ and $\mathrm{D}$ is compact, $\mathrm{D} \cap \partial \mathrm{U}=\emptyset$ so there exists a continuous map $\mu: \overline{\mathrm{U}} \rightarrow[0,1]$ with $\mu(\partial \mathrm{U})=0$ and $\mu(D)=1$. Define $J: \overline{\mathrm{U}} \rightarrow 2^{\mathrm{Y}}$ by $\mathrm{J}(\mathrm{x})=\mathrm{H}(\mathrm{x}, \mu(\mathrm{x}))$. Note $\mathrm{J} \in \mathrm{A}_{\partial \mathrm{u}}(\overline{\mathrm{U}}, \mathrm{Y} ; \mathrm{L}, \mathrm{T})$ and $\left.\mathrm{J}\right|_{\partial \mathrm{u}}=\left.\mathrm{F}\right|_{\partial u}$. Now since $F$ is $(L, T) \Phi$-essential in $A_{\partial u}(\bar{U}, Y ; L, T)$ there exists $x \in U$ with $(L+T)^{-1}(J+T)(x) \cap(L+T)^{-1}(\Phi+$ $T)(x) \neq \emptyset$ (i.e., $\left.(L+T)^{-1}\left(H_{\mu(x)}+T\right)(x) \cap(L+T)^{-1}(\Phi+T)(x) \neq \emptyset\right)$, and thus $x \in D$ so $\mu(x)=1$ and we are finished. 
Remark 2.21. If $\mathrm{E}$ is a normal topological vector space then the assumption that $\mathrm{D}$ (in the proof of Theorem 2.20) is compact, can be replaced by D is closed, in the statement (and proof) of Theorem 2.20.

Next we present a topological transversality theorem for $(L, T) \Phi$-essential maps. To achieve this we need to change Definition 2.19 (see Definition 2.23 below).

Definition 2.22. Let $F, G \in A_{\partial u}(\bar{U}, Y ; L, T)$. We say $F \cong G$ in $A_{\partial u}(\bar{U}, Y ; L, T)$ if there exists a map $\Psi$ : $\overline{\mathrm{U}} \times[0,1] \rightarrow 2^{\mathrm{Y}}$ with $(\mathrm{L}+\mathrm{T})^{-1}(\Psi(., \eta())+.\mathrm{T}().) \in A(\overline{\mathrm{U}}, \mathrm{E})$ for any continuous function $\eta: \overline{\mathrm{U}} \rightarrow[0,1]$ with $\eta(\partial \mathrm{U})=0,(\mathrm{~L}+\mathrm{T})^{-1}\left(\Psi_{\mathrm{t}}+\mathrm{T}\right)(\mathrm{x}) \cap(\mathrm{L}+\mathrm{T})^{-1}(\Phi+\mathrm{T})(\mathrm{x})=\emptyset$ for any $\mathrm{x} \in \mathrm{\partial U}$ and $\mathrm{t} \in[0,1], \Psi_{1}=\mathrm{F}, \Psi_{0}=\mathrm{G}$ and

$$
\left\{x \in \overline{\mathrm{U}}:(\mathrm{L}+\mathrm{T})^{-1}(\Phi+\mathrm{T})(\mathrm{x}) \cap(\mathrm{L}+\mathrm{T})^{-1}\left(\Psi_{\mathrm{t}}+\mathrm{T}\right)(\mathrm{x}) \neq \emptyset \text { for some } \mathrm{t} \in[0,1]\right\}
$$

is compact; here $\Psi_{t}(x)=\Psi(x, t)$.

The following condition will be assumed in our next two results:

$$
\cong \text { is an equivalence relation in } A_{\partial u}(\bar{U}, Y ; L, T) \text {. }
$$

Definition 2.23. Let $F \in A_{\partial u}(\bar{U}, Y ; L, T)$. We say $F$ is $(L, T) \Phi$-essential in $A_{\partial u}(\bar{U}, Y ; L, T)$ if for every map $\mathrm{J} \in \mathrm{A}_{\partial \mathrm{u}}(\overline{\mathrm{U}}, \mathrm{Y} ; \mathrm{L}, \mathrm{T})$ with $\left.\mathrm{J}\right|_{\partial \mathrm{u}}=\left.\mathrm{F}\right|_{\partial u}$ and $\mathrm{J} \cong \mathrm{F}$ in $A_{\partial \mathrm{u}}(\overline{\mathrm{U}}, \mathrm{Y} ; \mathrm{L}, \mathrm{T})$ there exists $x \in \mathrm{U}$ with $(\mathrm{L}+\mathrm{T})^{-1}(\mathrm{~J}+$ $\mathrm{T})(x) \cap(\mathrm{L}+\mathrm{T})^{-1}(\Phi+\mathrm{T})(\mathrm{x}) \neq \emptyset$. Otherwise $\mathrm{F}$ is $(\mathrm{L}, \mathrm{T}) \Phi$-inessential in $A_{\partial \mathrm{u}}(\overline{\mathrm{U}}, \mathrm{E})$, i.e., there exists a map $\mathrm{J} \in \mathrm{A}_{\partial \mathrm{u}}(\overline{\mathrm{U}}, \mathrm{Y} ; \mathrm{L}, \mathrm{T})$ with $\left.\mathrm{J}\right|_{\partial \mathrm{u}}=\left.\mathrm{F}\right|_{\partial \mathrm{u}}$ and $\mathrm{J} \cong \mathrm{F}$ in $A_{\partial \mathrm{u}}(\overline{\mathrm{U}}, \mathrm{Y} ; \mathrm{L}, \mathrm{T})$ with $(\mathrm{L}+\mathrm{T})^{-1}(\mathrm{~J}+\mathrm{T})(\mathrm{x}) \cap(\mathrm{L}+\mathrm{T})^{-1}(\Phi+$ $\mathrm{T})(\mathrm{x})=\emptyset$ for all $x \in \overline{\mathrm{U}}$.

Theorem 2.24. Let $\mathrm{E}$ and $\mathrm{Y}$ be topological vector spaces, $\mathrm{U}$ an open subset of $\mathrm{E}, \mathrm{L}: \operatorname{dom} \mathrm{L} \subseteq \mathrm{E} \rightarrow \mathrm{Y}$ a linear single valued map, $\mathrm{T} \in \mathrm{H}_{\mathrm{L}}(\mathrm{E}, \mathrm{Y})$, and assume (2.7) holds. Suppose $\mathrm{F} \in \mathrm{A}_{\partial \mathrm{u}}(\overline{\mathrm{U}}, \mathrm{Y} ; \mathrm{L}, \mathrm{T})$ and assume the following condition holds:

$$
\left\{\begin{array}{l}
\text { if there exists a map } \mathrm{G} \in \mathrm{A}_{\partial \mathrm{u}}(\overline{\mathrm{U}}, \mathrm{Y} ; \mathrm{L}, \mathrm{T}) \text { with } \mathrm{G} \cong \mathrm{F} \text { in } \mathrm{A}_{\partial \mathrm{u}}(\overline{\mathrm{U}}, \mathrm{Y} ; \mathrm{L}, \mathrm{T}) \\
\text { and }(\mathrm{L}+\mathrm{T})^{-1}(\mathrm{G}+\mathrm{T})(\mathrm{x}) \cap(\mathrm{L}+\mathrm{T})^{-1}(\Phi+\mathrm{T})(\mathrm{x})=\emptyset \text { for all } \mathrm{x} \in \overline{\mathrm{U}} \text { and } \\
\text { if } \mathrm{H} \text { is the map defined in Definition } 2.22 \text { and } \mu: \overline{\mathrm{U}} \rightarrow[0,1] \text { is any } \\
\text { continuous map with } \mu(\partial \mathrm{U})=0, \text { then } \\
\left\{x \in \overline{\mathrm{U}}:(\mathrm{L}+\mathrm{T})^{-1}(\Phi+\mathrm{T})(\mathrm{x}) \cap(\mathrm{L}+\mathrm{T})^{-1}\left(\mathrm{H}_{\mathrm{t} \mu(\mathrm{x})}+\mathrm{T}\right)(\mathrm{x}) \neq \emptyset \text { for some } \mathrm{t} \in[0,1]\right\} \text { is closed. }
\end{array}\right.
$$

Then, the following are equivalent:

(i). $\mathrm{F}$ is $(\mathrm{L}, \mathrm{T})$ Ф-inessential in $\mathrm{A}_{\partial \mathrm{u}}(\overline{\mathrm{U}}, \mathrm{Y} ; \mathrm{L}, \mathrm{T})$;

(ii). there exists a map $\mathrm{G} \in \mathrm{A}_{\partial \mathrm{u}}(\overline{\mathrm{U}}, \mathrm{Y} ; \mathrm{L}, \mathrm{T})$ with $\mathrm{G} \cong \mathrm{F}$ in $\mathrm{A}_{\mathrm{\partial u}}(\overline{\mathrm{U}}, \mathrm{Y} ; \mathrm{L}, \mathrm{T})$ and $(\mathrm{L}+\mathrm{T})^{-1}(\mathrm{G}+\mathrm{T})(\mathrm{x}) \cap(\mathrm{L}+$ $\mathrm{T})^{-1}(\Phi+\mathrm{T})(\mathrm{x})=\emptyset$ for all $\mathrm{x} \in \overline{\mathrm{U}}$.

Proof. (i) implies (ii) immediately. Next we prove (ii) implies (i). Suppose there exists a map $G \in$ $A_{\partial u}(\bar{U}, Y ; L, T)$ with $G \cong F$ in $A_{\partial u}(\bar{U}, Y ; L, T)$ and $(L+T)^{-1}(G+T)(x) \cap(L+T)^{-1}(\Phi+T)(x)=\emptyset$ for all $x \in \overline{\mathrm{U}}$. Let $\mathrm{H}: \overline{\mathrm{U}} \times[0,1] \rightarrow 2^{\mathrm{Y}}$ with $(\mathrm{L}+\mathrm{T})^{-1}(\mathrm{H}(., \eta())+.\mathrm{T}().) \in \mathrm{A}(\overline{\mathrm{U}}, \mathrm{E})$ for any continuous function $\eta: \bar{U} \rightarrow[0,1]$ with $\eta(\partial \mathrm{U})=0,(\mathrm{~L}+\mathrm{T})^{-1}\left(\mathrm{H}_{\mathrm{t}}+\mathrm{T}\right)(\mathrm{x}) \cap(\mathrm{L}+\mathrm{T})^{-1}(\Phi+\mathrm{T})(\mathrm{x})=\emptyset$ for any $\mathrm{x} \in \partial \mathrm{U}$ and $\mathrm{t} \in[0,1]$, $\mathrm{H}_{1}=\mathrm{F}, \mathrm{H}_{0}=\mathrm{G}$ (here $\mathrm{H}_{\mathrm{t}}(\mathrm{x})=\mathrm{H}(\mathrm{x}, \mathrm{t})$ ) and

$$
\left\{x \in \overline{\mathrm{U}}:(\mathrm{L}+\mathrm{T})^{-1}(\Phi+\mathrm{T})(\mathrm{x}) \cap(\mathrm{L}+\mathrm{T})^{-1}\left(\mathrm{H}_{\mathrm{t}}+\mathrm{T}\right)(\mathrm{x}) \neq \emptyset \text { for some } \mathrm{t} \in[0,1]\right\}
$$

is compact. Let

$$
\mathrm{D}=\left\{x \in \overline{\mathrm{U}}:(\mathrm{L}+\mathrm{T})^{-1}(\Phi+\mathrm{T})(\mathrm{x}) \cap(\mathrm{L}+\mathrm{T})^{-1}\left(\mathrm{H}_{\mathrm{t}}+\mathrm{T}\right)(\mathrm{x}) \neq \emptyset \text { for some } \mathrm{t} \in[0,1]\right\} .
$$

If $\mathrm{D}=\emptyset$ we are finished. Next suppose $\mathrm{D} \neq \emptyset$. Note $\mathrm{D}$ is compact, $\mathrm{D} \cap \partial \mathrm{U}=\emptyset$, so there exists a continuous map $\mu: \overline{\mathrm{U}} \rightarrow[0,1]$ with $\mu(\partial \mathrm{U})=0$ and $\mu(\mathrm{D})=1$. Define $\mathrm{J}: \overline{\mathrm{U}} \rightarrow 2^{\gamma}$ by $\mathrm{J}(\mathrm{x})=\mathrm{H}(\mathrm{x}, \mu(\mathrm{x}))$. It is easy to check (a slight modification of the argument in Theorem 2.14) that $J \in A_{\partial u}(\bar{U}, Y ; L, T)$, $\left.\mathrm{J}\right|_{\text {au }}=\left.\mathrm{H}_{0}\right|_{\text {əu }}=\left.\mathrm{F}\right|_{\text {au }},(\mathrm{L}+\mathrm{T})^{-1}(\Phi+\mathrm{T})(\mathrm{x}) \cap(\mathrm{L}+\mathrm{T})^{-1}(\mathrm{~J}+\mathrm{T})(\mathrm{x})=\emptyset$ for $\mathrm{x} \in \overline{\mathrm{U}}$ and $\mathrm{J} \cong \mathrm{F}$ in $A_{\text {au }}(\overline{\mathrm{U}}, \mathrm{Y} ; \mathrm{L}, \mathrm{T})$. Thus $F$ is $(L, T) \Phi$-inessential in $A_{\partial u}(\bar{U}, Y ; L, T)$. 
Theorem 2.25. Let $\mathrm{E}$ and $\mathrm{Y}$ be topological vector spaces, $\mathrm{U}$ an open subset of $\mathrm{E}, \mathrm{L}: \operatorname{dom} \mathrm{L} \subseteq \mathrm{E} \rightarrow \mathrm{Y}$ a linear singlevalued map, $\mathrm{T} \in \mathrm{H}_{\mathrm{L}}(\mathrm{E}, \mathrm{Y})$, and assume (2.7) and (2.8) hold. Suppose $\mathrm{F}$ and $\mathrm{G}$ are two maps in $\mathrm{A}_{\mathrm{\partial u}}(\overline{\mathrm{U}}, \mathrm{Y} ; \mathrm{L}, \mathrm{T})$ with $\mathrm{F} \cong \mathrm{G}$ in $\mathrm{A}_{\partial \mathrm{u}}(\overline{\mathrm{U}}, \mathrm{Y} ; \mathrm{L}, \mathrm{T})$. Then $\mathrm{F}$ is $(\mathrm{L}, \mathrm{T}) \Phi$-essential in $\mathrm{A}_{\partial \mathrm{u}}(\overline{\mathrm{U}}, \mathrm{Y} ; \mathrm{L}, \mathrm{T})$ if and only if $\mathrm{G}$ is $(\mathrm{L}, \mathrm{T}) \Phi$-essential in $A_{\partial u}(\bar{U}, Y ; L, T)$.

Remark 2.26. If $E$ is a normal topological vector space then the assumption that $D$ in the proof of Theorem 2.24 is compact (see Definition 2.22), can be replaced by D is closed, in the proof of Theorem 2.24 and Theorem 2.25 (modify Definition 2.22 accordingly).

Motivated by the above theory, we note that it is also possible to discuss $\Phi$-epi maps in a general setting. For completeness we present the theory here. We fix a $\Phi \in B(\bar{U}, E)$.

Definition 2.27. We say $F \in B_{\Phi}(\bar{U}, E)$ if $F \in B(\bar{U}, E)$ and $F(x) \subseteq \Phi(x)$ for $x \in \partial U$.

Definition 2.28. A map $F \in A_{\partial U}(\bar{U}, E)$ is $\Phi$-epi if for every map $G \in B_{\Phi}(\bar{U}, E)$ there exists $x \in U$ with $\mathrm{F}(\mathrm{x}) \cap \mathrm{G}(\mathrm{x}) \neq \emptyset$.

Remark 2.29. Suppose $F \in A_{\partial u}(\bar{U}, E)$ is $\Phi$-epi. Then there exists $x \in U$ with $F(x) \cap \Phi(x) \neq \emptyset$ (take $G=\Phi$ in Definition 2.28).

Our next result can be called the "homotopy property" for $\Phi$-epi maps. In our result E will be a topological vector space so automatically a completely regular space.

Theorem 2.30. Let $\mathrm{E}$ be a topological vector space and $\mathrm{U}$ an open subset of $\mathrm{E}$. Suppose $\mathrm{F} \in \mathrm{A}_{\partial \mathrm{U}}(\overline{\mathrm{U}}, \mathrm{E})$ is $\Phi$-epi and $\mathrm{H}: \overline{\mathrm{U}} \times[0,1] \rightarrow 2^{\mathrm{E}}$ with $\mathrm{H}(\mathrm{x}, 0)=\{0\}$ for $\mathrm{x} \in \partial \mathrm{U}$ and $\mathrm{F}()-.\mathrm{H}(., 1) \in \mathrm{A}(\overline{\mathrm{U}}, \mathrm{E})$. In addition assume the following conditions hold:

$$
\begin{aligned}
& \left\{\begin{array}{l}
\text { if } \mathrm{F}_{1} \in \mathrm{B}(\overline{\mathrm{U}}, \mathrm{E}), \text { then } \mathrm{F}_{1}(.)+\mathrm{H}(., \mu(.)) \in \mathrm{B}(\overline{\mathrm{U}}, \mathrm{E}) \\
\text { for any continuous map } \mu: \overline{\mathrm{U}} \rightarrow[0,1] \text { with } \mu(\partial \mathrm{U})=0,
\end{array}\right. \\
& \{\{x \in \overline{\mathrm{U}}: \mathrm{F}(\mathrm{x}) \cap[\Phi(x)+\mathrm{H}(\mathrm{x}, \mathrm{t})] \neq \emptyset \text { for some } \mathrm{t} \in[0,1]\} \text { does not intersect du, }
\end{aligned}
$$

and

$$
\left\{\begin{array}{l}
\text { for any map } \mathrm{G} \in \mathrm{B}_{\Phi}(\overline{\mathrm{U}}, \mathrm{E}), \text { the set } \\
\{\mathrm{x} \in \overline{\mathrm{U}}: \mathrm{F}(\mathrm{x}) \cap[\mathrm{G}(\mathrm{x})+\mathrm{H}(\mathrm{x}, \mathrm{t})] \neq \emptyset \text { for some } \mathrm{t} \in[0,1]\} \text { is compact. }
\end{array}\right.
$$

Then, $\mathrm{F}()-.\mathrm{H}(., 1): \overline{\mathrm{U}} \rightarrow \mathrm{K}(\mathrm{E})$ is $\Phi$-epi.

Proof. Let $\mathrm{G} \in \mathrm{B}_{\Phi}(\overline{\mathrm{U}}, \mathrm{E})$. We must show that there exists $x \in \mathrm{U}$ with $[\mathrm{F}(\mathrm{x})-\mathrm{H}(\mathrm{x}, 1)] \cap \mathrm{G}(\mathrm{x}) \neq \emptyset$. Let

$$
\mathrm{D}=\{x \in \overline{\mathrm{U}}: \mathrm{F}(\mathrm{x}) \cap[\mathrm{G}(\mathrm{x})+\mathrm{H}(\mathrm{x}, \mathrm{t})] \neq \emptyset \text { for some } \mathrm{t} \in[0,1]\} .
$$

When $t=0$, we have $G()+.H(., 0) \in B_{\Phi}(\bar{U}, E)$ since from (2.9) we have $G()+.H(., 0) \in B(\bar{U}, E)$ and for $x \in \partial \mathrm{U}$ we have $\mathrm{G}(\mathrm{x})+\mathrm{H}(\mathrm{x}, 0)=\mathrm{G}(\mathrm{x}) \subseteq \Phi(\mathrm{x})$ and this together with the fact that $\mathrm{F}$ is $\Phi$-epi yields $\mathrm{D} \neq \emptyset$. Note from (2.11) that $\mathrm{D}$ is compact. Next we note that (2.10) guarantees that $\mathrm{D} \cap \partial \mathrm{U}=\emptyset$ (note if $x \in \partial \mathrm{U}$ then $\mathrm{F}(\mathrm{x}) \cap[\mathrm{G}(\mathrm{x})+\mathrm{H}(\mathrm{x}, \mathrm{t})] \subseteq \mathrm{F}(\mathrm{x}) \cap[\Phi(\mathrm{x})+\mathrm{H}(\mathrm{x}, \mathrm{t})])$. Thus there exists a continuous map $\mu: \overline{\mathrm{U}} \rightarrow[0,1]$ with $\mu(\partial \mathrm{U})=0$ and $\mu(\mathrm{D})=1$.

Define a map J : $\overline{\mathrm{U}} \rightarrow 2^{\mathrm{E}}$ by

$$
J(x)=G(x)+H(x, \mu(x)) .
$$

Note $J \in B(\bar{U}, E)$ from (2.9) and for $x \in$ dU we have $J(x)=G(x)+H(x, \mu(x))=G(x)+H(x, 0)=G(x) \subseteq$ $\Phi(x)$. Thus $J \in B_{\Phi}(\bar{U}, E)$. Now since $F$ is $\Phi$-epi there exists $x \in U$ with $F(x) \cap J(x) \neq \emptyset$, i.e., $F(x) \cap$ $[G(x)+H(x, \mu(x))] \neq \emptyset$. Thus $x \in D$ and as a result $\mu(x)=1$. Consequently $F(x) \cap[G(x)+H(x, 1)] \neq \emptyset$ so $[\mathrm{F}(\mathrm{x})-\mathrm{H}(\mathrm{x}, 1)] \cap \mathrm{G}(\mathrm{x}) \neq \emptyset$.

Remark 2.31. If $\mathrm{E}$ is a normal topological vector space then the assumption that $\mathrm{D}$ (in the proof of Theorem 2.30 ) is compact, can be replaced by D is closed, in the statement (and proof) of Theorem 2.30. 
Our next result can be called the "coincidence property" for $\Phi$-epi maps.

Theorem 2.32. Let $\mathrm{E}$ be a topological vector space and $\mathrm{U}$ an open subset of $\mathrm{E}$. Suppose $\mathrm{F} \in \mathrm{A}_{\partial \mathrm{u}}(\overline{\mathrm{U}}, \mathrm{E})$ is $\Phi$-epi, $\mathrm{G} \in \mathrm{B}(\overline{\mathrm{U}}, \mathrm{E})$ and assume the following conditions hold:

$\{\mu(.) \mathrm{G}()+.(1-\mu().) \Phi(.) \in \mathrm{B}(\overline{\mathrm{U}}, \mathrm{E})$ for any continuous map $\mu: \overline{\mathrm{U}} \rightarrow[0,1]$ with $\mu(\partial \mathrm{U})=0$,

$\{\{x \in \overline{\mathrm{U}}: \mathrm{F}(\mathrm{x}) \cap[\mathrm{t} \mathrm{G}(\mathrm{x})+(1-\mathrm{t}) \Phi(\mathrm{x})] \neq \emptyset$ for some $\mathrm{t} \in[0,1]\}$ does not intersect $\partial \mathrm{U}$, and

$\{\{x \in \overline{\mathrm{U}}: \mathrm{F}(\mathrm{x}) \cap[\mathrm{t} \mathrm{G}(\mathrm{x})+(1-\mathrm{t}) \Phi(\mathrm{x})] \neq \emptyset$ for some $\mathrm{t} \in[0,1]\}$ is compact.

Then, there exists $\mathrm{x} \in \overline{\mathrm{U}}$ with $\mathrm{F}(\mathrm{x}) \cap \mathrm{G}(\mathrm{x}) \neq \emptyset$.

Proof. Let

$$
\mathrm{D}=\{x \in \overline{\mathrm{U}}: \mathrm{F}(\mathrm{x}) \cap[\mathrm{t} \mathrm{G}(\mathrm{x})+(1-\mathrm{t}) \Phi(\mathrm{x})] \neq \emptyset \text { for some } \mathrm{t} \in[0,1]\} .
$$

When $t=0$ note $F(x) \cap \Phi(x) \neq \emptyset$ for some $x \in U$ since $F \in A_{\partial u}(\bar{U}, E)$ is $\Phi$-epi, so $D \neq \emptyset$. Note $D$ is compact and $\mathrm{D} \cap \partial \mathrm{U}=\emptyset$ from (2.13). Thus there exists a continuous map $\mu: \bar{U} \rightarrow[0,1]$ with $\mu(\partial \mathrm{U})=0$ and $\mu(\mathrm{D})=1$.

Define a map $\mathrm{J}: \overline{\mathrm{U}} \rightarrow 2^{\mathrm{E}}$ by

$$
J(x)=\mu(x) G(x)+(1-\mu(x)) \Phi(x) .
$$

Now (2.12) guarantees that $J \in B(\bar{U}, E)$ and for $x \in \partial U$ we have $J(x)=0+\Phi(x)=\Phi(x)$, so $J \in B_{\Phi}(\bar{U}, E)$. Now since $F$ is $\Phi$-epi there exists $x \in U$ with $F(x) \cap J(x) \neq \emptyset$. Thus $x \in D$ and as a result $\mu(x)=1$. Consequently $\mathrm{F}(\mathrm{x}) \cap \mathrm{G}(\mathrm{x}) \neq \emptyset$.

Remark 2.33. If $\mathrm{E}$ is a normal topological vector space then the assumption that $\mathrm{D}$ (in the proof of Theorem 2.32) is compact, can be replaced by D is closed, in the statement (and proof) of Theorem 2.32.

Let $E$ and $Y$ be topological vector spaces, and $U$ an open subset of $E$. Also let $L: \operatorname{dom} L \subseteq E \rightarrow Y$ be a linear single-valued map and $T \in \mathrm{H}_{\mathrm{L}}(\mathrm{E}, \mathrm{Y})$. We fix a $\Phi \in \mathrm{B}(\overline{\mathrm{U}}, \mathrm{Y} ; \mathrm{L}, \mathrm{T})$.

Definition 2.34. We say $F \in B_{\Phi}(\bar{U}, Y ; L, T)$ if $F \in B(\bar{U}, Y ; L, T)$ and $(L+T)^{-1}(F+T)(x) \subseteq(L+T)^{-1}(\Phi+$ $\mathrm{T})(\mathrm{x})$ for $x \in \partial \mathrm{u}$.

Definition 2.35. A map $F \in A_{\partial u}(\bar{U}, Y ; L, T)$ is $(L, T) \Phi$-epi if for every map $G \in B_{\Phi}(\bar{U}, Y ; L, T)$ there exists $x \in \mathrm{U}$ with $(\mathrm{L}+\mathrm{T})^{-1}(\mathrm{~F}+\mathrm{T})(\mathrm{x}) \cap(\mathrm{L}+\mathrm{T})^{-1}(\mathrm{G}+\mathrm{T})(\mathrm{x}) \neq \emptyset$.

Remark 2.36. Suppose $F \in A_{\partial u}(\bar{U}, Y ; L, T)$ is $(L, T) \Phi$-epi. Then there exists $x \in U$ with $(L+T)^{-1}(F+$ $\mathrm{T})(\mathrm{x}) \cap(\mathrm{L}+\mathrm{T})^{-1}(\Phi+\mathrm{T})(\mathrm{x}) \neq \emptyset($ take $\mathrm{G}=\Phi$ in Definition 2.35).

Theorem 2.37. Let $\mathrm{E}$ and $\mathrm{Y}$ be topological vector spaces, $\mathrm{U}$ an open subset of $\mathrm{E}, \mathrm{L}: \operatorname{dom} \mathrm{L} \subseteq \mathrm{E} \rightarrow \mathrm{Y}$ a linear single-valued map and $\mathrm{T} \in \mathrm{H}_{\mathrm{L}}(\mathrm{E}, \mathrm{Y})$. Suppose $\mathrm{F} \in \mathrm{A}_{\partial \mathrm{u}}(\overline{\mathrm{U}}, \mathrm{Y} ; \mathrm{L}, \mathrm{T})$ is $(\mathrm{L}, \mathrm{T}) \Phi$-epi and $\mathrm{H}: \overline{\mathrm{U}} \times[0,1] \rightarrow 2^{\mathrm{Y}}$ with $(\mathrm{L}+\mathrm{T})^{-1} \mathrm{H}(x, 0)=\{0\}$ for $\mathrm{x} \in \partial \mathrm{U}$ and $\mathrm{F}()-.\mathrm{H}(., 1) \in \mathrm{A}(\overline{\mathrm{U}}, \mathrm{Y} ; \mathrm{L}, \mathrm{T})$. In addition assume the following conditions hold:

$$
\begin{aligned}
& \left\{\begin{array}{l}
\text { if } \mathrm{F}_{1} \in \mathrm{B}(\overline{\mathrm{U}}, \mathrm{Y} ; \mathrm{L}, \mathrm{T}), \text { then } \mathrm{F}_{1}(.)+\mathrm{H}(., \mu(.)) \in \mathrm{B}(\overline{\mathrm{U}}, \mathrm{Y} ; \mathrm{L}, \mathrm{T}) \\
\text { for any continuous map } \mu: \overline{\mathrm{U}} \rightarrow[0,1] \text { with } \mu(\partial \mathrm{U})=0,
\end{array}\right. \\
& \left\{\begin{array}{l}
\left\{x \in \overline{\mathrm{U}}:(\mathrm{L}+\mathrm{T})^{-1}(\mathrm{~F}+\mathrm{T})(\mathrm{x}) \cap(\mathrm{L}+\mathrm{T})^{-1}[\Phi(\mathrm{x})+\mathrm{H}(\mathrm{x}, \mathrm{t})+\mathrm{T}(\mathrm{x})] \neq \emptyset\right. \\
\text { for some } \mathrm{t} \in[0,1]\} \text { does not intersect } \partial \mathrm{U},
\end{array}\right.
\end{aligned}
$$

and

$$
\left\{\begin{array}{l}
\text { for any map } \mathrm{G} \in \mathrm{B}_{\Phi}(\overline{\mathrm{U}}, \mathrm{Y} ; \mathrm{L}, \mathrm{T}) \text { the set } \\
\left\{x \in \overline{\mathrm{U}}:(\mathrm{L}+\mathrm{T})^{-1}(\mathrm{~F}+\mathrm{T})(\mathrm{x}) \cap(\mathrm{L}+\mathrm{T})^{-1}[\mathrm{G}(\mathrm{x})+\mathrm{H}(\mathrm{x}, \mathrm{t})+\mathrm{T}(\mathrm{x})] \neq \emptyset\right. \\
\text { for some } \mathrm{t} \in[0,1]\} \text { is compact. }
\end{array}\right.
$$

Then, $\mathrm{F}()-.\mathrm{H}(., 1)$ is $(\mathrm{L}, \mathrm{T})$ Ф-epi. 
Proof. Let $\mathrm{G} \in \mathrm{B}_{\Phi}(\overline{\mathrm{U}}, \mathrm{Y} ; \mathrm{L}, \mathrm{T})$ and

$$
\mathrm{D}=\left\{x \in \overline{\mathrm{U}}:(\mathrm{L}+\mathrm{T})^{-1}(\mathrm{~F}+\mathrm{T})(\mathrm{x}) \cap(\mathrm{L}+\mathrm{T})^{-1}[\mathrm{G}(\mathrm{x})+\mathrm{H}(\mathrm{x}, \mathrm{t})+\mathrm{T}(\mathrm{x})] \neq \emptyset \text { for some } \mathrm{t} \in[0,1]\right\} .
$$

When $t=0$ we have $G()+.H(., 0) \in B(\bar{U}, Y ; L, T)$ and for $x \in \partial U$ we have $(L+T)^{-1}[G(x)+H(x, 0)+$ $\mathrm{T}(\mathrm{x})]=(\mathrm{L}+\mathrm{T})^{-1}(\mathrm{G}+\mathrm{T})(\mathrm{x}) \subseteq(\mathrm{L}+\mathrm{T})^{-1}(\Phi+\mathrm{T})(\mathrm{x})$, so $\mathrm{G}()+.\mathrm{H}(., 0) \in \mathrm{B}_{\Phi}(\overline{\mathrm{U}}, \mathrm{Y} ; \mathrm{L}, \mathrm{T})$ and this together with the fact that $F$ is $(L, T) \Phi$-epi yields $D \neq \emptyset$. Also $D$ is compact and $D \cap \partial U=\emptyset$, so there exists a continuous map $\mu: \overline{\mathrm{U}} \rightarrow[0,1]$ with $\mu(\partial \mathrm{U})=0$ and $\mu(\mathrm{D})=1$. Define a map $\mathrm{J}: \overline{\mathrm{U}} \rightarrow 2^{\gamma}$ by

$$
J(x)=G(x)+H(x, \mu(x)) .
$$

Now $J \in B(\bar{U}, Y ; L, T)$ and for $x \in \partial U$ we have $(L+T)^{-1}(J+T)(x)=(L+T)^{-1}[G(x)+H(x, 0)+T(x)]=$ $(L+T)^{-1}(G+T)(x) \subseteq(L+T)^{-1}(\Phi+T)(x)$. Thus $J \in B_{\Phi}(\bar{U}, Y ; L, T)$ so since $F$ is $(L, T) \Phi$-epi there exists $x \in U$ with $(L+T)^{-1}(F+T)(x) \cap(L+T)^{-1}(J+T)(x) \neq \emptyset$. Thus $x \in D$ so $\mu(x)=1$ and we are finished.

Remark 2.38. If $\mathrm{E}$ is a normal topological vector space then the assumption that $\mathrm{D}$ (in the proof of Theorem 2.37) is compact, can be replaced by D is closed, in the statement (and proof) of Theorem 2.37.

Theorem 2.39. Let $\mathrm{E}$ and $\mathrm{Y}$ be topological vector spaces, $\mathrm{U}$ an open subset of $\mathrm{E}, \mathrm{L}: \operatorname{dom} \mathrm{L} \subseteq \mathrm{E} \rightarrow \mathrm{Y}$ a linear single-valued map, and $\mathrm{T} \in \mathrm{H}_{\mathrm{L}}(\mathrm{E}, \mathrm{Y})$. Suppose $\mathrm{F} \in \mathrm{A}_{\partial \mathrm{u}}(\overline{\mathrm{U}}, \mathrm{Y} ; \mathrm{L}, \mathrm{T})$ is $(\mathrm{L}, \mathrm{T}) \Phi-e p i, \mathrm{G} \in \mathrm{B}(\overline{\mathrm{U}}, \mathrm{Y} ; \mathrm{L}, \mathrm{T})$, and assume the following conditions hold:

$$
\begin{aligned}
& \left\{\begin{array}{l}
\mu(.) \mathrm{G}(.)+(1-\mu(.)) \Phi(.) \in \mathrm{B}(\overline{\mathrm{U}}, \mathrm{Y} ; \mathrm{L}, \mathrm{T}) \text { for any } \\
\text { continuous map } \mu: \overline{\mathrm{U}} \rightarrow[0,1] \text { with } \mu(\partial \mathrm{U})=0,
\end{array}\right. \\
& \left\{\begin{array}{l}
\left\{x \in \overline{\mathrm{U}}:(\mathrm{L}+\mathrm{T})^{-1}(\mathrm{~F}+\mathrm{T})(\mathrm{x}) \cap(\mathrm{L}+\mathrm{T})^{-1}[\mathrm{t} \mathrm{G}(\mathrm{x})+(1-\mathrm{t}) \Phi(\mathrm{x})+\mathrm{T}(\mathrm{x})] \neq \emptyset\right. \\
\text { for some } \mathrm{t} \in[0,1]\} \text { does not intersect } \partial \mathrm{U},
\end{array}\right.
\end{aligned}
$$

and

$$
\left\{\begin{array}{l}
\left\{x \in \overline{\mathrm{U}}:(\mathrm{L}+\mathrm{T})^{-1}(\mathrm{~F}+\mathrm{T})(\mathrm{x}) \cap(\mathrm{L}+\mathrm{T})^{-1}[\mathrm{t} \mathrm{G}(\mathrm{x})+(1-\mathrm{t}) \Phi(\mathrm{x})+\mathrm{T}(\mathrm{x})] \neq \emptyset\right. \\
\text { for some } \mathrm{t} \in[0,1]\} \text { is compact. }
\end{array}\right.
$$

Then, there exists $x \in \overline{\mathrm{U}}$ with $(\mathrm{L}+\mathrm{T})^{-1}(\mathrm{~F}+\mathrm{T})(\mathrm{x}) \cap(\mathrm{L}+\mathrm{T})^{-1}(\mathrm{G}+\mathrm{T})(\mathrm{x}) \neq \emptyset$.

Proof. Let

$$
\mathrm{D}=\left\{x \in \overline{\mathrm{U}}:(\mathrm{L}+\mathrm{T})^{-1}(\mathrm{~F}+\mathrm{T})(\mathrm{x}) \cap(\mathrm{L}+\mathrm{T})^{-1}[\mathrm{t} \mathrm{G}(\mathrm{x})+(1-\mathrm{t}) \Phi(\mathrm{x})+\mathrm{T}(\mathrm{x})] \neq \emptyset \text { for some } \mathrm{t} \in[0,1]\right\} .
$$

Now $\mathrm{D} \neq \emptyset$ is compact and $\mathrm{D} \cap \partial \mathrm{U}=\emptyset$. Thus there exists a continuous map $\mu: \overline{\mathrm{U}} \rightarrow[0,1]$ with $\mu(\partial \mathrm{U})=0$ and $\mu(\mathrm{D})=1$. Define a map $\mathrm{J}: \overline{\mathrm{U}} \rightarrow 2^{\mathrm{Y}}$ by

$$
J(x)=\mu(x) G(x)+(1-\mu(x)) \Phi(x) .
$$

Now $J \in B(\bar{U}, Y ; L, T)$ and for $x \in$ oU we have $(L+T)^{-1}(J+T)(x)=(L+T)^{-1}[0+(\Phi+T)(x)]$, so $J \in$ $\mathrm{B}_{\Phi}(\overline{\mathrm{U}}, \mathrm{Y} ; \mathrm{L}, \mathrm{T})$. Now, since $\mathrm{F}$ is $(\mathrm{L}, \mathrm{T}) \Phi$-epi, there exists $\mathrm{x} \in \mathrm{U}$ with $(\mathrm{L}+\mathrm{T})^{-1}(\mathrm{~F}+\mathrm{T})(\mathrm{x}) \cap(\mathrm{L}+\mathrm{T})^{-1}(\mathrm{~J}+$ $\mathrm{T})(\mathrm{x}) \neq \emptyset$. Thus, $x \in \mathrm{D}$ and as a result, $\mu(x)=1$, so we are finished.

Remark 2.40. If $\mathrm{E}$ is a normal topological vector space then the assumption that $\mathrm{D}$ (in the proof of Theorem 2.39 ) is compact, can be replaced by D is closed, in the statement (and proof) of Theorem 2.39.

\section{References}

[1] R. P. Agarwal, D. O’Regan, Nonlinear essential maps of Mönch, 1-set contractive demicompact and monotone (S)+ type, J. Appl. Math. Stochastic Anal., 14 (2001), 293-301. 2.11

[2] R. P. Agarwal, D. O'Regan, A note on the topological transversality theorem for acyclic maps, Appl. Math. Lett., 18 (2005), 17-22. 2.16 
[3] F. E. Browder, Nonlinear operators and nonlinear equations of evolution in Banach spaces, Nonlinear functional analysis, Proc. Sympos. Pure Math., Vol. XVIII, Part 2, Chicago, Ill., (1968), 1-308, Amer. Math. Soc., Providence, R. I., (1976). 2

[4] F. E. Browder, Fixed point theory and nonlinear problems, Bull. Amer. Math. Soc. (N.S.), 9 (1983), 1-39. 2, 2.11, 2.16

[5] M. Furi, M. Martelli, A. Vignoli, On the solvability of nonlinear operator equations in normed spaces, Ann. Mat. Pura Appl., 124 (1980), 321-343. 1

[6] G. Gabor, L. Górniewicz, M. Ślosarski, Generalized topological essentiality and coincidence points of multivalued maps, Set-Valued Var. Anal., 17 (2009), 1-19. 1

[7] A. Granas, Sur la méthode de continuité de Poincaré, C. R. Acad. Sci. Paris Sr. A-B, 282 (1976), 983-985. 1

[8] T. Kato, Demicontinuity, hemicontinuity and monotonicity, Bull. Amer. Math. Soc., 70 (1964), 548-550. 2

[9] T. Kato, Demicontinuity, hemicontinuity and monotonicity, II, Bull. Amer. Math. Soc., 73 (1967), 886-889. 2

[10] D. O'Regan, Continuation methods based on essential and 0-epi maps, Acta Appl. Math., 54 (1998), 319-330. 1

[11] D. O'Regan, Continuation theorems for acyclic maps in topological spaces, Commun. Appl. Anal., 13 (2009), 39-45. 2.16

[12] D. O'Regan, Homotopy principles for d-essential acyclic maps, J. Nonlinear Convex Anal., 14 (2013), 415-422. 2.16

[13] D. O'Regan, Coincidence points for multivalued maps based on $\Phi$-epi and $\Phi$-essential maps, Dynam. Systems Appl., 24 (2015), 143-154. 1

[14] D. O'Regan, R. Precup, Theorems of Leray-Schauder type and applications, Series in Mathematical Analysis and Applications, Gordon and Breach Science Publishers, Amsterdam, (2001). 1, 2.11 